Jurnal Ilmu Sosial dan Pendidikan (JISIP)

Vol. 5 No. 3 Juli 2021

Terakreditasi Peringkat 5 (No. SK: 85/M/KPT/2020)

e-ISSN : 2656-6753, p-ISSN: 2598-9944

DOI: 10.36312/jisip.v5i3.2208/http://ejournal.mandalanursa.org/index.php/JISIP/index

\title{
Penelitian Evaluasi: Kajian Evaluasi Kinerja Institusi aspek Kinerja Penelitian
}

\author{
Syahrir ${ }^{1}$, Awaluddin Tjalla ${ }^{2}$, Richardus Eko Indrajit $^{3}$ \\ ${ }^{1,2,3}$ Universitas Negeri Jakarta
}

\begin{tabular}{|c|c|}
\hline Article Info & ABSTRACT \\
\hline Article history: & Tujuan artikel ini menganalisis konsep evaluasi kinerja institusi aspek penelitian. \\
\hline Received Article: Juli 142021 & Hasil analisis pada beberapa artikel disimpulkan bahwa evaluasi kinerja institusi \\
\hline Publication : 15 Juli, 2021 & $\begin{array}{l}\text { aspek kinerja penelitian bergantung pada beberapa factor dasar dalam evaluasi } \\
\text { dampak kinerja penelitian untuk pengambilan keputusan pembinaan kinerja } \\
\text { penelitian yaitu kerangka/sistematika proposal penelitian, teori konsep penelitian }\end{array}$ \\
\hline $\begin{array}{l}\text { Keywords: } \\
\text { Institutional Performance, }\end{array}$ & $\begin{array}{l}\text { evaluasi institusı, rekam jejak tim penelitı, manajemen penelitian, dampak penelitian, } \\
\text { mobilisasi penelitian dan kelompok partisipan penelitian. }\end{array}$ \\
\hline
\end{tabular}

Research Performance.

Article Info

Article history:

Received Article: Juli 142021

Publication : 15 Juli, 2021

\section{Corresponding Author:}

\section{Syahrir}

Universitas Negeri Jakarta

Syahrirmandala85@gmail.com

\begin{tabular}{l} 
Abstract \\
\hline The purpose of this article is to analyze the evaluation of the institutional evaluation \\
of research aspects. The results of the analysis on several articles that are spoken, \\
performance evaluation, evaluation of several basic factors in evaluating the impact \\
of research for decision making on the development of research proposal \\
performance, theory of institutional evaluation research concepts, research team \\
trails, research management, research impact, research mobilization and research \\
participant groups. \\
This is an open access article under the Lisensi Creative Commons Atribusi- \\
BerbagiSerupa 4.0 Internasional
\end{tabular}

\section{PENDAhuluan}

Perubahan dalam sistem pendidikan di berbagai negara telah mengembangkan model baru dari manajemen kelembagaan dan pengajaran, serta mekanisme untuk mengevaluasi kinerja pendidik. Minat terhadap kualitas mereka telah meningkat dan berkontribusi pada peningkatan para pendidik (Matdle Diaz, 2015). System pendidikan bisa berjalan dengan baik dalam sebuah institusi apabila kinerja karyawannya menunjukkan pelayanan yang baik. Evaluasi kinerja karyawan perlu dilakukan oleh sebuah institusi.

Perkembangan minat pekerjaan multi/inter/trans disipliner (MIT-D), yang membutuhkan peningkatan tingkat pengetahuan dan interaksi produksi bersama. Banyak penelitian yang membahas tema ini dengan pendekatan yang berbeda seperti sifat subjek ilmiah transversal, konsep integrasi pengetahuan, dan dinamika kelompok penelitian untuk bekerja secara konsisten dalam kolaborasi. Faktor terpenting bagi lembaga pemerintah yang bertanggung jawab atas penilaian dan pendanaan peneliti, tim peneliti, atau penelitian program pascasarjana (Talita Moreira de Oliveira, 2018). Perkembangan penelitian evaluasi terus menemukan fenomena baru di dunia pendidikan tinggi maupun pusat penelitian. 
Penelitian evaluasi pada evaluasi penelitian tersebar luas di dunia akademisi, dan dapat mengakibatkan perubahan pola publikasi, struktur manajemen, dan praktik kerja. Penelitian Sara Karlsson mengeksplorasi fenomena yang relatif baru dimana para pemimpin universitas memulai proyek penelitian evaluasi untuk tujuan strategis internal. Dua proyek yang dilakukan oleh Royal Institute of Technology, Swedia, pada tahun 2008 dan 2012 diambil sebagai contoh kasus. (Sara Karlsson, 2017).

Semakin kompleksnya masalah sosial dan ilmiah, pusat penelitian telah muncul untuk memfasilitasi pelaksanaan penelitian di luar batas disiplin dan kelembagaan. Sementara mereka telah menjadi mapan pada universitas di dunia, pusat penelitian mengajukan beberapa pertanyaan kritis untuk evaluasi penelitian. Pendekatan evaluasi yang ada yang dirancang untuk menilai universitas, departemen, proyek, atau peneliti. individu gagal memahami beberapa karakteristik inti dari pusat penelitian dan pesertanya, termasuk keragaman peneliti yang terlibat, pada titik mana mereka bergabung dan meninggalkan pusat penelitian, atau intensitas partisipasi mereka (Omar Kassab, 2020). Pengembangan kinerja institusi yaitu lembaga penelitian atau pusat penelitian mengevaluasi kinerja penelitian sebagai rekam jejak dalam pengambilan keputusan untuk pendanaan penelitian pada setiap tim peneliti.

Berbagai lembaga pendanaan, lembaga pembuat kebijakan, dan organisasi penelitian beroperasi dengan model dan metode yang berbeda untuk dampak penilaian penelitian. Dampak tidak berarti sama di seluruh institusi, geografi, dan budaya penelitian. Keragaman konseptual ini tercermin dalam jumlah metode dan kerangka kerja yang digunakan untuk melacak, mendemonstrasikan, menilai, dan memberi insentif pada dampak penelitian di komunitas SSH Eropa dan sekitarnya. Keragaman dampaknya agenda di SSH mencerminkan tren yang lebih luas dalam evaluasi dampak. Penelitian evaluasi dampak telah menunjukkan bahwa organisasi penelitian publik tidak hanya melepaskan manfaatnya kepada masyarakat mengikuti model pertumbuhan dan penerapan linier. Sebaliknya, efek penelitian dunia nyata terjadi pada tahapan yang berbeda dalam proses penelitian, mulai dari penyebaran pengetahuan dan mobilisasi pengetahuan hingga aplikasi jangka panjang dan efek dinamis (David Budtz Pedersen, 2020).

Penelitian Williams menjelaskan bahwa bagaimana penelitian dinilai mempengaruhi jenis pengetahuan apa yang dihargai, diberi insentif, dan dihargai. Unsur yang semakin penting dari evaluasi penelitian kontemporer adalah pengukuran dampak penelitian yang lebih luas (misalnya manfaat bagi masyarakat, budaya atau ekonomi). Meskipun pengukuran dampak telah banyak diperdebatkan, wilayah tersebut kurang berteori dan didominasi oleh keharusan kebijakan penelitian pragmatis (Williams, 2020)

\section{METODE PENELITIAN}

Penelitian Matdle Diaz melakukan studi pendidikan komparatif memungkinkan studi tentang perbedaan dan persamaan antara sistem pendidikan yang berbeda. Penelitian tersebut, yang terdiri dari evaluasi pendidikan, telah mempelajari perilaku mengajar dari 10 (sepuluh ) dosen universitas dari sebuah universitas Spanyol-Universitas La Laguna, dan 7 (tujuh) dari sebuah universitas di Meksiko (Matdle Diaz, 2015). Penelitian menggunakan metode evaluasi komparatif yang mengevaluasi 17 dosen di universitas Universitas La Laguna sejumlah 10 (sepuluh) orang, dan 7 (tujuh) dari universitas di Meksiko yang mengukur dampak penelitian ketika dosen mengajar menggunakan kerangka proposal penelitian. Hasil penelitian Matdle Diaz menjelaskan tingkah laku dosen pada saat mengajar dalam mengembangkan pembelajaran. Validitas silang diimplementasikan dalam dua sistem pengajaran yang berbeda, menegaskan penerapan instrumen dalam metode observasi yang digunakan. Terlepas dari perbedaan dalam setiap sistem pendidikan, para dosen yang diteliti memiliki lebih banyak kesamaan daripada perbedaan. Pola perilaku umum dalam semua kasus adalah dorongan untuk Keterlibatan - Jawaban dosen yang menunjukkan kelas yang aktif dan interaktif saat mendorong siswa. 
Dalam semua kasus yang dipelajari, Penjelasan dosen menghasilkan pola signifikan yang berbeda satu sama lain. Namun demikian, mereka memiliki konsekuensi yang sama, Dorongan Keterlibatan yang memungkinkan untuk menunjukkan jenis dosen yang memiliki komponen konstruktivis penting. Ini mendorong keterlibatan siswa dalam pengembangan sesi dan membantu mereka untuk berpikir secara refleks tentang isi penjelasan. Perilaku pendampingan tidak sering dilakukan pada semua dosen yang dianalisis. Di UdG tidak ada pola yang signifikan untuk file bimbingan perilaku, yang hanya berlangsung dalam pelajaran praktik dan tidak terjadi dengan semua dosen ULL. Ini menunjukkan bahwa terdapat aktivitas praktis terpisah di ULL dan dalam bingkai ruang kelas terintegrasi di UdG. Komponen prosedur tidak terlalu banyak di salah satu dari kedua universitas tersebut. Namun, penampakannya Revisi Non Verbal lebih sering, tetapi itu juga bukan pola yang umum. Salah satu bagian penting dari kinerja guru adalah praktik pendidikan yang baik yang dilakukan oleh guru, yaitu apa yang harus mereka lakukan untuk meningkatkan kualitas pengajaran dan pembelajaran yang sesuai. Bagian penting dari praktik pendidikan yang baik adalah memberikan umpan balik dengan menjawab pertanyaan-pertanyaan siswa. Pada dosen yang diteliti kami mengamati adanya pola yang signifikan antara keterlibatan mahasiswa dengan jawaban yang diberikan oleh dosen, sehingga dapat dipastikan bahwa mereka semua memiliki praktik pendidikan yang baik. Selain itu, ada ketertarikan untuk mendorong keterlibatan mahasiswa baik jika mahasiswa melakukan intervensi atas inisiatif sendiri (Student's Involvement) maupun saat mahasiswa menjawab dosen, seperti yang terlihat saat mengikuti kedua perilaku tersebut, secara praktis di semua kasus. dengan penguatan dari dosen Hasil yang diperoleh menunjukkan bagaimana dosen yang dinilai menampilkan kinerja mengajar yang sesuai. Aspek ini tidak aneh karena semuanya mengajukan diri untuk studi ini. Dapat ditunjukkan bahwa profil guru dapat bervariasi pada dosen dengan kinerja profesional yang biasa-biasa saja atau tidak sesuai . Namun, institusi akademik akan memutuskan apakah perlu membuat prosedur evaluasi. Ketika perilaku dianalisis secara rinci, ini memungkinkan analisis perilaku yang sangat spesifik yang diterjemahkan ke dalam kemungkinan membuat dan menerapkan rencana tindakan perbaikan (Matdle Diaz, 2015).

Hasil penelitian Talita Moreira de Oliveira menjelaskan bahwa kerangka kerja MIT-D sistemik untuk program pascasarjana dan penilaian tim peneliti. Ini memperhitungkan penelitian historis dan terkini dalam penilaian program pascasarjana dan sistem penilaian pascasarjana nasional yang didasarkan pada tinjauan sejawat dan informasi deskriptif yang dilakukan oleh badan publik Brasil. Kerangka kerja ini memiliki tiga tingkat analisis, yang memungkinkan partisipasi berbagai pengambil keputusan, menggunakan pendekatan berbeda untuk mengeksplorasi empat dimensi analitis (kemampuan individu, kolaborasi, konten, dan keluaran / hasil). Kami telah menganalisis penerapannya dalam pendekatan scientometric dan penilaian penelitian yang dilakukan oleh lembaga pemerintah. Kerangka yang diusulkan cocok dan relevan secara luas bagi peneliti dan pengambil keputusan untuk menganalisis kursus dan tim peneliti. menggunakan pendekatan yang berbeda untuk mengeksplorasi empat dimensi analitis (kemampuan individu, kolaborasi, konten, dan keluaran / hasil). Kami telah menganalisis penerapannya dalam pendekatan scientometric dan penilaian penelitian yang dilakukan oleh lembaga pemerintah. Kerangka yang diusulkan cocok dan relevan secara luas bagi peneliti dan pengambil keputusan untuk menganalisis kursus dan tim peneliti. menggunakan pendekatan yang berbeda untuk mengeksplorasi empat dimensi analitis (kemampuan individu, kolaborasi, konten, dan keluaran / hasil). Kami telah menganalisis penerapannya dalam pendekatan scientometric dan penilaian penelitian yang dilakukan oleh lembaga pemerintah. Kerangka yang diusulkan cocok dan relevan secara luas bagi peneliti dan pengambil keputusan untuk menganalisis kursus dan tim peneliti (Talita Moreira de Oliveira, 2018).

Berdasarkan perspektif sosiologis, artikel ini mengintervensi konteks ini dengan membingkai kembali dampak penelitian sebagai pencapaian dan pemeliharaan modal (yaitu kekuasaan atau status simbolis) di berbagai bidang di luar akademisi. Ia berpendapat bahwa dampak penelitian terjadi dipersimpangan bidang kekuasaan ini. Artikel tersebut menunjukkan bahwa dampak melibatkan 
berbagai kombinasi modal dari bidang ilmiah, bidang politik, bidang aplikasi, bidang media, dan bidang ekonomi, yang masing-masing memberikan kredibilitas, otoritas, utilitas, visibilitas, dan bobot. Dalam mengeksplorasi bentuk nilai dan nilai yang mendukung pengejaran legitimasi di bidang ini, artikel ini memberikan kerangka teoritis baru untuk memahami dampak penelitian dan penilaiannya (Williams, 2020).

Penelitian ini memeriksa komponen metodologi utama yang digunakan untuk menilai dampak penelitian dengan membandingkan kelebihan dan kekurangan masing-masing metode. Studi ini menemukan bahwa dampak penelitian adalah konsep yang sangat kompleks dan diperdebatkan dalam literatur SSH. Berdasarkan pluralisme metodologis yang kuat yang muncul dalam literatur, kami menyimpulkan bahwa ada banyak ruang bagi peneliti, universitas, dan lembaga pendanaan untuk membuat alat penilaian dampak yang diarahkan ke misi tertentu sambil menghindari indikator penampung-semua dan metrik universal (David Budtz Pedersen, 2020).

artikel ini memperkenalkan pendekatan lanjutan untuk evaluasi ex post pusat penelitian. Ini dibangun di atas desain kuasi-eksperimental dalam kelompok, analisis bibliometrik, dan statistik multilevel untuk menilai efek kausal rata-rata dan individu dari afiliasi pusat penelitian pada peserta di sepanjang tiga dimensi kinerja penelitian. Pendekatan evaluasi diuji dengan data arsip dari sebuah pusat di bidang ilmu keberlanjutan. Berlawanan dengan kepercayaan yang dianut secara luas, kami menemukan bahwa partisipasi dalam pusat penelitian tidak menimbulkan kerugian bagi para peneliti sejauh menyangkut kinerja penelitian mereka. Namun, lintasan individu sangat bervariasi. Pendekatan evaluasi diuji dengan data kearsipan dari pusat di bidang ilmu keberlanjutan. Berlawanan dengan kepercayaan yang dianut secara luas, kami menemukan bahwa partisipasi di pusat penelitian tidak menimbulkan kerugian bagi peneliti sejauh menyangkut kinerja penelitian mereka. Namun, lintasan individu sangat bervariasi. Pendekatan evaluasi diuji dengan data arsip dari sebuah pusat di bidang ilmu keberlanjutan. Berlawanan dengan kepercayaan yang dianut secara luas, kami menemukan bahwa partisipasi di pusat penelitian tidak menimbulkan kerugian bagi peneliti sejauh menyangkut kinerja penelitian mereka. Namun, lintasan individu sangat bervariasi (Omar Kassab, 2020).

penelitian ini menemukan bahwa konsekuensi awal dari kedua evaluasi tersebut kurang berhubungan dengan hasil penelitian, dan lebih kepada manajemen penelitian. Data bibliometrik tidak menunjukkan dampak yang dapat diukur pada pola publikasi. Sebaliknya, evaluasi telah berkontribusi pada peningkatan fokus pada kepemimpinan, komunikasi, dan ketertiban administrasi yang baik. Kecenderungan bermain game terlihat jelas, tetapi begitu pula wacana intra-akademis yang direvitalisasi tentang kualitas penelitian. Lebih lanjut, penelitian ini menemukan variasi dalam bagaimana evaluasi penelitian berdampak pada kelompok penelitian yang berbeda. Yang penting, dampaknya paling besar pada kelompok-kelompok yang telah diidentifikasi sebagai yang paling tidak berhasil menurut kriteria evaluasi yang spesifik. Kelompok-kelompok tersebut dapat mengalami perubahan besar dalam menanggapi hasil evaluasi. Disimpulkan bahwa latihan evaluasi membawa komponen normatif yang kuat yang dapat digunakan untuk tujuan manajemen pusat untuk memperjuangkan lebih banyak koherensi budaya di dalam universitas. Dalam istilah teoretis, evaluasi penelitian diartikan sebagai gagasan perjalanan, yang memiliki tekanan substansial untuk menyesuaikan diri tetapi juga dapat memicu perdebatan kritis tentang kualitas penelitian (Sara Karlsson, 2017).

\section{KESIMPULAN}

Berdasarkan hasil analisis pada beberapa artikel disimpulkan bahwa evaluasi kinerja institusi aspek kinerja penelitian bergantung pada beberapa factor dasar dalam evaluasi dampak kinerja penelitian untuk pengambilan keputusan pembinaan kinerja penelitian yaitu kerangka/sistematika proposal penelitian, teori konsep penelitian evaluasi institusi, rekam jejak tim peneliti, manajemen penelitian, dampak penelitian, mobilisasi penelitian dan kelompok partisipan penelitian. 


\section{DAFTAR PUSTAKA}

David Budtz Pedersen, J. F. (2020). Methods for mapping the impact of social sciences and humanities -A literature review. Research Evaluation, O(0 Special Section), 1-18.

Matdle Diaz, A. B. (2015). Evaluation of the Teaching Performance of University Lecturers: Comparison between Mexico and Spain. Journal of Curriculum and Teaching, 4(2), 5361.

Omar Kassab, R. M.-D. (2020). Introducing and testing an advanced quantitative methodological approach for the evaluation of research centers: a case study on sustainability science. Research Evaluation, 29(2), 139-149.

Sara Karlsson. (2017). Evaluation as a travelling idea: Assessing the consequences of Research Assessment Exercises. Research Evaluation, 26(2), 55-65.

Talita Moreira de Oliveira, L. A. (2018). Multi/inter/transdisciplinary assessment: A systemic framework proposal to evaluate graduate courses and research teams. Research Evaluation, 1-14.

Williams, K. (2020). Playing the fields: Theorizing research impact and its assessment. Research Evaluation, O(0), 1-12.

Al-Balushi, K., \& Al-Balushi, S. (2018). Effectiveness of Brain-Based Learning for Grade Eight Students' Direct and Postponed Retention in Science. International Journal of Instruction, 11, 525-538. https://doi.org/10.12973/iji.2018.11336a

Adiansha, A. A., \& Sumantri, M. S. (2017). The Effect of Brain Based Learning Model and Creative Thinking on the Ability of Mathematics Concept of Elementary Students, 5(12), 11951199. https://doi.org/10.12691/education-5-12-4

Atta, A., \& Safein, M. (2017). Engaging ESP Students with Brain-Based Learning for Improved Listening Skills , Vocabulary Retention and Motivation. English Language Teaching, 10(12). https://doi.org/10.5539/elt.v10n12p182

Carayannis, E. G. (Ed.). (2013). Mathematical Creativity. In Encyclopedia of Creativity, Invention, Innovation and Entrepreneurship (p. 1228). New York, NY: Springer New York. https://doi.org/10.1007/978-1-4614-3858-8_100618

Chaijaroen, S., \& Samat, C. (2018). Design and Development of Learning Innovation Enhancing Learning Potential Using Brain-Based Learning. In T.-T. Wu, Y.-M. Huang, R. Shadiev, L. Lin, \& A. I. Starčič (Eds.), Innovative Technologies and Learning (pp. 189-195). Cham: Springer International Publishing.

Charlesworth, R. (2005). Prekindergarten Mathematics: Connecting with National Standards. Early Childhood Education Journal, 32(4), 229-236. https://doi.org/10.1007/s10643-004-14237

Duman, B. (2010). The Effects of Brain-Based Learning on the Academic Achievement of Students with Different Learning Styles. Educational Sciences: Theory \& Practice, 10(4), 20772103.

Ellerton, N. F. (2018). Book Review: NCTM's Compendium: finding a balance between historical details, contemporary practices, and future resources. Jinfa Cai (Ed.) (2017) Compendium for research in mathematics education. Educational Studies in Mathematics, 99(1), 109123. https://doi.org/10.1007/s10649-018-9827-2

Englar, R. (2018). Tracking Veterinary Students' Acquisition of Communication Skills and Clinical Communication Confidence by Comparing Student Performance in the First and TwentySeventh Standardized Client Encounters. Journal of Veterinary Medical Education, 1-23. https://doi.org/10.3138/jvme.0917-117r1

Ervynck, G. (1991). Mathematical Creativity. In D. Tall (Ed.), Advanced Mathematical Thinking (pp. 42-53). Dordrecht: Springer Netherlands. https://doi.org/10.1007/0-306-47203-1_3 
Glas, E. (2002). Klein's Model of Mathematical Creativity. Science \& Education, 11(1), 95-104. https://doi.org/10.1023/A:1013075819948

Goldin, G. A. (2017). Mathematical creativity and giftedness: perspectives in response. ZDM, 49(1), 147-157. https://doi.org/10.1007/s11858-017-0837-9

GÖZÜYEŞİL, E., \& DİKİCİ, A. (2014). The Effect of Brain Based Learning on Academic Achievement: A Meta-analytical Study. Educational Sciences: Theory \& Practice, 14(2), 642-648. https://doi.org/10.12738/estp.2014.2.2103

Hayal Yavuz Mumcu., Aktürk, T. (2017). An Analysis Of The Reasoning Skills Of Pre-Service Teachers In The Context Of Mathematical Thinking. European Journal of Education Studies, 3(5), 225-254. https://doi.org/10.5281/zenodo.495700

Haylock, D. W. (1987). A framework for assessing mathematical creativity in school chilren. Educational Studies in Mathematics, 18(1), 59-74. https://doi.org/10.1007/BF00367914

Heymann, H. W. (2003). Mathematics Instruction from the Perspective of General Education. In Why Teach Mathematics? A Focus on General Education (pp. 83-223). Dordrecht: Springer Netherlands. https://doi.org/10.1007/978-94-017-3682-4_3

Hole, A., Grønmo, L. S., \& Onstad, T. (2018). The dependence on mathematical theory in TIMSS, PISA and TIMSS Advanced test items and its relation to student achievement. LargeScale Assessments in Education, 6(1), 3. https://doi.org/10.1186/s40536-018-0055-0

Hoshino, R. (2018). Supporting Mathematical Creativity Through Problem Solving. In A. Kajander, J. Holm, \& E. J. Chernoff (Eds.), Teaching and Learning Secondary School Mathematics: Canadian Perspectives in an International Context (pp. 367-375). Cham: Springer International Publishing. https://doi.org/10.1007/978-3-319-92390-1_34

Inocian, R. B. (2015). Integrated Arts-based Teaching ( IAT ) Model for Brain-based Learning. Journal of Curriculum and Teaching, 4(2), 130-143. https://doi.org/10.5430/jct.v4n2p130

Kattou, M., Kontoyianni, K., Pitta-Pantazi, D., \& Christou, C. (2013). Connecting mathematical creativity to mathematical ability. ZDM, 45(2), 167-181. https://doi.org/10.1007/s11858012-0467-1

Koşar, G. (2018). European Journal of Education Studies Improving Knowledge Retention Via Establishing Brain-Based Learning Environment. European Journal of Education Studies, 4(9), 208-218. https://doi.org/10.5281/zenodo.1298918

Krummheuer, G., Leuzinger-Bohleber, M., Müller-Kirchof, M., Münz, M., \& Vogel, R. (2013). Explaining the mathematical creativity of a young boy: an interdisciplinary venture between mathematics education and psychoanalysis. Educational Studies in Mathematics, 84(2), 183-199. https://doi.org/10.1007/s10649-013-9505-3

Leikin, R., \& Lev, M. (2013). Mathematical creativity in generally gifted and mathematically excelling adolescents: what makes the difference? ZDM, 45(2), 183-197. https://doi.org/10.1007/s11858-012-0460-8

Lev, M., \& Leikin, R. (2017). The Interplay Between Excellence in School Mathematics and General Giftedness: Focusing on Mathematical Creativity. In R. Leikin \& B. Sriraman (Eds.), Creativity and Giftedness: Interdisciplinary perspectives from mathematics and beyond (pp. 225-238). Cham: Springer International Publishing. https://doi.org/10.1007/978-3319-38840-3_14

Luria, S. R., Sriraman, B., \& Kaufman, J. C. (2017). Enhancing equity in the classroom by teaching for mathematical creativity. ZDM, 49(7), 1033-1039. https://doi.org/10.1007/s11858017-0892-2

Mazzola, G., Guitart, R., Ho, J., Lubet, A., Mannone, M., Rahaim, M., \& Thalmann, F. (2017). Mathematical Models of Creativity. In The Topos of Music III: Gestures: Musical Multiverse Ontologies (pp. 1001-1082). Cham: Springer International Publishing. 
https://doi.org/10.1007/978-3-319-64481-3_12

McComas, W. F. (2014). Trends in International Mathematics and Science Study (TIMSS). In W. F. McComas (Ed.), The Language of Science Education: An Expanded Glossary of Key Terms and Concepts in Science Teaching and Learning (p. 108). Rotterdam: SensePublishers. https://doi.org/10.1007/978-94-6209-497-0_97

McLeod, D. B., Stake, R. E., Schappelle, B. P., Mellissinos, M., \& Gierl, M. J. (1996). Setting the Standards. In S. A. Raizen \& E. D. Britton (Eds.), Bold Ventures: Case Studies of U.S. Innovations in Mathematics Education (pp. 13-132). Dordrecht: Springer Netherlands. https://doi.org/10.1007/978-94-011-7111-3_2

Merenda, R. C. (2000). Numeracy encounters in a book bag: Meeting the NCTM standards. Early Childhood Education Journal, 27(3), 151-157. https://doi.org/10.1007/BF02694228

Muhammad 'Azmi Nuha., S. B. Waluya., I. J. (2018). Mathematical Creative Process Wallas Model in Students Problem Posing with Lesson Study Approach. International Journal of Instruction, 11(2), 527-538. https://doi.org/https://doi.org/10.12973/iji.2018.11236a

Muir, A. (1988). The psychology of mathematical creativity. The Mathematical Intelligencer, 10(1), 33-37. https://doi.org/10.1007/BF03023849

NCES, N. C. for E. S. (2017). Highlights From TIMSS and TIMSS Advanced 2015, 1-58.

Oluwole Pratt, E. (2002). Aligning Mathematics Teacher Work Sample Content with Selected NCTM Standards: Implications for Preservice Teacher Education. Journal of Personnel Evaluation in Education, 16(3), 175-190. https://doi.org/10.1023/A:1020857122306

Organisation for Economic Cooperation and Development (OECD). (2015a). Pisa 2015 Result Fokus, 2015-2016.

Organisation for Economic Cooperation and Development (OECD). (2015b). PISA 2015 Results (Volume I): Excellence and Equity in Education, PISA (Vol. I). Paris: OECD Publishing. https://doi.org/10.1787/9789264266490-en

Organisation for Economic Cooperation and Development (OECD). (2016). Result From PISA 2015Programme For International Student Assesment (PISA), 1-8.

Organisation for Economic Cooperation and Development (OECD). (2017a). PISA 2015 Assessment and Analytical Framework: Science, Reading, Mathematic, Financial Literacy and Collaborative Problem Solving, revised edition, PISA. Paris: OECD Publishing. https://doi.org/10.1787/9789264281820-en

Organisation for Economic Cooperation and Development (OECD). (2017b). PISA 2015 Results (Volume III): Students' Well-Being, PISA (Vol. III). Paris: OECD Publishing. https://doi.org/http://dx.doi.org/10.1787/9789264273856-en

Organisation for Economic Cooperation and Development (OECD). (2017c). PISA 2015 Results (Volume IV): Students' Financial Literacy, PISA. OECD Publishing (Vol. IV). Paris: OECD Publishing. https://doi.org/http://dx.doi.org/10.1787/9789264270282-en

Pitta-Pantazi, D., Kattou, M., \& Christou, C. (2018). Mathematical Creativity: Product, Person, Process and Press. In F. M. Singer (Ed.), Mathematical Creativity and Mathematical Giftedness: Enhancing Creative Capacities in Mathematically Promising Students (pp. 27-53). Cham: Springer International Publishing. https://doi.org/10.1007/978-3-31973156-8_2

Rachmadtullah, R., Ms, Z., \& Sumantri, M. S. (2018). Development of computer - based interactive multimedia: study on learning in elementary education. International Journal of Engineering \& Technolog, 7(4), 2035-2038. https://doi.org/10.14419/ijet.v7i4.16384

Saleh, M., Charitas, R., Prahmana, I., \& Isa, M. (2018). Improving the Reasoning Ability of Elementary School Student Through the Indonesian Realistic. Journal on Mathematics Education, 9(1), 41-54.

Samat, C., Saengjan, P., Chaijaroen, S., Kanjug, I., \& Vongtathum, P. (2018). Designing of the 
Learning Innovation Enhance Learning Potential of the Learners Using Brain-Based Learning. In T.-T. Wu, Y.-M. Huang, R. Shadiev, L. Lin, \& A. I. Starčič (Eds.), Innovative Technologies and Learning (pp. 196-204). Cham: Springer International Publishing.

Samsudin, N. S., Samsuddin, I., \& Yusof, A. F. (2018). Creativity in Mathematical Thinking Through Constructivist Learning Approach for Architecture Students. In R. Saian \& M. A. Abbas (Eds.), Proceedings of the Second International Conference on the Future of ASEAN (ICoFA) 2017 -- Volume 2 (pp. 133-142). Singapore: Springer Singapore.

Schindler, M., Joklitschke, J., \& Rott, B. (2018). Mathematical Creativity and Its SubdomainSpecificity. Investigating the Appropriateness of Solutions in Multiple Solution Tasks. In F. M. Singer (Ed.), Mathematical Creativity and Mathematical Giftedness: Enhancing Creative Capacities in Mathematically Promising Students (pp. 115-142). Cham: Springer International Publishing. https://doi.org/10.1007/978-3-319-73156-8_5

Shabatat, K., \& Al-Tarawneh, M. (2016). The Impact of a Teaching-Learning Program Based on a Brain-Based Learning on the Achievement of the Female Students of 9th Grade in Chemistry. Higher Education Studies, 6(2), 162. https://doi.org/10.5539/hes.v6n2p162

Shriki, A. (2010). Working like real mathematicians: developing prospective teachers' awareness of mathematical creativity through generating new concepts. Educational Studies in Mathematics, 73(2), 159-179. https://doi.org/10.1007/s10649-009-9212-2

Sorge, V. (2014). Combining Systems for Mathematical Creativity (Invited Talk). In G. A. ArandaCorral, J. Calmet, \& F. J. Martín-Mateos (Eds.), Artificial Intelligence and Symbolic Computation (pp. 7-8). Cham: Springer International Publishing.

Sriraman, B. (2008). The characteristics of mathematical creativity. ZDM, 41(1), 13. https://doi.org/10.1007/s11858-008-0114-z

Sriraman, B., Haavold, P., \& Lee, K. (2013). Mathematical creativity and giftedness: a commentary on and review of theory, new operational views, and ways forward. ZDM, 45(2), 215225. https://doi.org/10.1007/s11858-013-0494-6

Sriraman, B., Haavold, P., \& Lee, K. (2014). Creativity in Mathematics Education. Encyclopedia of Mathematics Education, 109-115. https://doi.org/10.1007/978-94-007-4978-8_33

Sriraman, B., \& Pizzulli, M. (2005). Balancing mathematics education research and the NCTM standards. ZDM, 37(5), 431-436. https://doi.org/10.1007/s11858-005-0033-1

Sriraman, B., Yaftian, N., \& Lee, K. H. (2011). Mathematical Creativity and Mathematics Education. In B. Sriraman \& K. H. Lee (Eds.), The Elements of Creativity and Giftedness in Mathematics (pp. 119-130). Rotterdam: SensePublishers. https://doi.org/10.1007/978-946091-439-3_8

Sumantri, M. S. (2016). The Effect of Formative Testing and Self- Directed Learning on Mathematics Learning Outcomes. International Electronic Journal of Elementary Education, 8(3), 507-524. Retrieved from https://files.eric.ed.gov/fulltext/EJ1096528.pdf

Suparta, I. N. (2018). The Effect Of Brain Based Learning On Second Grade Junior Students' Mathematics Conceptual Understanding On Polyhedron. Journal on Mathematics Education, 9(1), 145-156. Retrieved from https://files.eric.ed.gov/fulltext/EJ1173645.pdf

Syahputra, E. (2018). Differences in Metacognition and Mathematical Communication Ability Between Students Taught Using Problem Based Learning Model and Numbered Head Together Cooperative Learning Model at SMP Kartika I-2 Medan. Journal of Education and Practice, 9, 30-37.

Van Harpen, X. Y., \& Sriraman, B. (2013). Creativity and mathematical problem posing: an analysis of high school students' mathematical problem posing in China and the USA. Educational Studies in Mathematics, 82(2), 201-221. https://doi.org/10.1007/s10649-012-9419-5

Waree, C. (2017). An Increasing of Primary School Teachers? Competency in Brain-Based Learning. International Education Studies, 10(3), 176. https://doi.org/10.5539/ies.v10n3p176 
Wessels, H. M. (2017). Exploring Aspects of Creativity in Mathematical Modelling. In G. A. Stillman, W. Blum, \& G. Kaiser (Eds.), Mathematical Modelling and Applications: Crossing and Researching Boundaries in Mathematics Education (pp. 491-501). Cham: Springer International Publishing. https://doi.org/10.1007/978-3-319-62968-1_41

Yasar, D. M. (2017). Brain Based Learning in Science Education in Turkey: Descriptive Content and Meta Analysis of Dissertations. Journal of Education and Practice, 8(9), 161-168. Retrieved from http://libproxy.library.wmich.edu/login?url=https://search.proquest.com/docview/19133 54524? accountid=15099 